\title{
Inflammation is a modulator of the insulin-like growth factor (IGF)/IGF-binding protein system inducing reduced bioactivity of IGFs in cystic fibrosis
}

Maria E Street, Maria A Ziveri, Cinzia Spaggiari, Isabella Viani, Cecilia Volta, Gian Luigi Grzincich, Raffaele Virdis and Sergio Bernasconi

Department of Paediatrics, University of Parma, Via Gramsci, 14, 43100 Parma, Italy

(Correspondence should be addressed to M E Street; Email: mariaelisabeth.street@unipr.it)

\begin{abstract}
Objective: In inflammatory bowel diseases, increased serum interleukin (IL)- 6 levels are associated with high serum insulin-like growth factor-binding protein 2 (IGFBP-2) levels, and cytokines modify the insulin-like growth factor (IGF)/IGFBP system in models in vitro. In cystic fibrosis (CF) the IGF/IGFBP system has not been extensively studied, and relationships with proinflammatory cytokines have not been explored. The aim of this study was to investigate the IGF/IGFBP system and verify changes dependent on IL-1 $\beta$, IL- 6 , tumour necrosis factor $\alpha$ (TNF $\alpha$ ), and insulin.

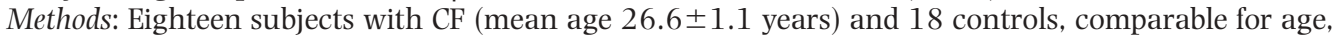
sex, and body mass index, were enrolled. Serum IGF-I, IGF-II, IGFBP-2, IGFBP-3, IL-1 $\beta$, IL-6, TNF $\alpha$, insulin and C-peptide were measured. Different molecular forms of IGFBP-2 and IGFBP-3 were investigated by Western immunoblotting. The patients were analysed as a whole and as two subgroups depending on established clinical criteria (Swachman-Kulczycki score).

Results: Patients had higher serum concentrations of IL-1 $\beta$, IL-6, TNF $\alpha$ and IGFBP-2 than controls. Serum concentrations of IGF-I and IGF-II were significantly lower and insulin and C-peptide levels significantly increased in CF compared with healthy controls whereas IGFBP-3 serum concentrations were similar, with comparable IGF-I/IGFBP-3 and decreased IGF-I/IGFBP-2 and IGF-II/IGFBP-2 molar ratios. From correlation analysis we detected a significant positive correlation between IGFBP-2 and IL-6 and a negative correlation between IGFBP-2 and IGFBP-3.

Conclusions: Our findings suggest that inflammation is an important modulator of the IGF/IGFBP system with an overall reduction in IGF bioactivity in CF.
\end{abstract}

European Journal of Endocrinology 154 47-52

\section{Introduction}

Impaired growth and delayed pubertal development are often described in chronic inflammatory diseases. Much data in the literature refer to inflammatory bowel diseases $(1-4)$. Few papers have studied modifications of growth factors in cystic fibrosis (CF). Cellular growth and proliferation, differentiation and apoptosis are mainly dependent on the effect of the growth hormone $(\mathrm{GH}) /$ insulin-like growth factor (IGF)/IGF-binding protein (IGFBP) axis. Growth delay in $\mathrm{CF}$ has been attributed to calorie and protein malnutrition due to anorexia, malabsorption and increased resting energy expenditure $(5,6)$. Generally, most of these patients have catch-up growth during treatment on dietary management consisting in high caloric food intake $(7,8)$. However, at least $20-30 \%$ of $\mathrm{CF}$ patients present with childhood growth delay and/or weight deficit $(9-12)$. In CF, serum IGF-I levels have been described to be normal (13) or below the normal range for age and it has been suggested that this could be secondary to liver dysfunction, impaired glucose tolerance, pubertal delay or chronic inflammation $(9,14)$.

IGF-I and IGFBP-3 serum concentrations in CF show a trend to increase and normalize after antibiotic treatment (15), suggesting that infection and inflammation might also play a role in regulating the IGF/IGFBP system. The finding of low IGF-I serum concentrations lead to the hypothesis of peripheral GH resistance. However, in 1999 (16) a study in adult patients with CF reported normal spontaneous GH secretion and release after stimulation with arginine. The report a few years later of low serum IGF-I, increased IGFBP-3 proteolysis and poor growth in transgenic mice overexpressing interleukin (IL)-6 supports the hypothesis that inflammatory mediators per se could modulate the IGF/IGFBP system $(17,18)$. 
In CF the inflammatory response to chronic inflammation is similar to that elicited by lipopolysaccharide and is mediated mainly by cytokines as tumour necrosis factor $\alpha$ (TNF $\alpha)$, IL-1, IL-6 and IL-8 (19). We have previously shown in vitro that IL-1 $\beta$ and IL-6 modify IGFBP secretion into conditioned media (20), and in vivo, in inflammatory bowel diseases, that IGFBP-2 concentrations are increased together with IL-6, IL-1 and C-reactive protein (21).

The aim of this study was to investigate whether inflammation in $\mathrm{CF}$ was related to changes in the IGF/IGFBP system. We investigated whether IL-1 IL-6, TNF $\alpha$ or insulin were related to changes in IGFI, IGF-II, IGFBP-2 and IGFBP-3.

\section{Materials and methods}

\section{Subjects}

Eighteen consecutive patients in our CF clinic (26.6 \pm 1.2 years, 6 males and 12 females) and 18 control subjects ( $28.0 \pm 1.2$ years, 4 males and 14 females), were enrolled into the study. Clinical details of patients and controls are shown in Table 1. The two groups were comparable for chronological age, sex and body mass index (BMI) and all had attained pubertal stage 5 according to the criteria of Marshall and Tanner $(22,23)$. The diagnosis of $\mathrm{CF}$ had been confirmed in all by genetic analysis and a sweat test. All had exogenous pancreatic insufficiency that required enzymatic supplementation and were treated with on-going antibiotic therapy. Two patients had been taking steroids for at least 3 months $(0.15 \mathrm{mg} / \mathrm{kg}$ per day of prednisone) and none were receiving azitromycin at the time of the study. One patient was excluded from the study for being diabetic and having signs of liver dysfunction. All but one patient tested positive for Pseudomonas aeruginosa infection, and one also had Burkholderia cepacia infection. C-reactive protein serum concentrations were assayed in all patients at the time of the study.

\section{Auxology observations}

Height and weight were measured in all subjects, and BMI was calculated accordingly. BMI, height and target height are expressed as standard deviation scores (SDS) using Italian reference data (24).

\section{Pulmonary function}

Standard pulmonary function tests were performed the same day as the blood samples were taken. For statistical analysis the forced expiratory volume in $1 \mathrm{~s}$ (FEV1) was expressed as a percentage of the reference value (25).

\section{Subgroups of subjects}

The patients were subdivided into two groups according to the Shwachman-Kulczycki scoring system (general activity, physical examination, nutrition and X-ray findings) (26). Group 1 were patients $(n=10)$ with scores of 71-100 (mildly affected) and group 2 were patients $(n=8)$ with scores of 41-70 (severely affected) (26). Control subjects were enrolled from young physicians training at our medical school and were healthy at the time of the study.

\section{Assays}

Blood samples were drawn after an overnight fast between 0800 and $0900 \mathrm{~h}$. The blood was kept on ice until centrifugation at $2000 \mathrm{~g} / \mathrm{min}$ for $10 \mathrm{~min}$ at $4^{\circ} \mathrm{C}$. The serum was then aliquoted and stored at $-80^{\circ} \mathrm{C}$ until assayed. Total serum IGF-I was measured using a RIA method (Nichols Institute Diagnostics, CA, USA). The coefficients of variation (CVs) were $3 \%$ (intra-assay) and $8.4 \%$ (inter-assay), respectively. Prior to assaying, serum samples were acid-ethanolprecipitated to avoid interference of binding proteins. Serum IGF-II and IGFBP-3 were measured using an immunoradiometric assay method (Diagnostic System Laboratories, Webster, TX, USA). The CVs were 5.3 and $1.9 \%$ (intra-assay) and $8.7 \%$ and $3.9 \%$ (inter-assay), respectively. Serum IGFBP-2 was assayed

Table 1 Clinical data of patients and controls.

\begin{tabular}{lcc}
\hline & CF & Controls \\
\hline Number (males, females) & $18(6,12)$ & $18(4,14)$ \\
Chronological age (years) & $26.6 \pm 1.2$ & $28.0 \pm 1.2$ \\
BMI SDS & $-0.3 \pm 0.2($ range: $-1.7-+1.2)$ & $0.1 \pm 0.2($ range: $-1.8-+1.6)$ \\
Height SDS & $-0.7 \pm 0.2^{*}$ & $0.5 \pm 0.2$ \\
Target height SDS & $-0.4 \pm 0.3$ & $-0.1 \pm 0.2$ \\
Total protein (g/dl) & $5.7 \pm 0.1$ & $0.7 \pm 0.2$ \\
Glucose (mg/dl) & $0.8 \pm 0.1$ & \\
AST (IU/l) & $22.3 \pm 2.6$ & \\
ALT (IU/l) & $24.5 \pm 3.9$ &
\end{tabular}

BMI SDS, body mass index expressed as standard deviation score (SDS); total protein (NI. 6-8.2 g/dl); AST, aspartate aminotransferase (NI. <40 UI/I); ALT, alanine aminotransferase (NI. <40 Ul/I); fasting serum glucose (NI. 60-110 mg/dl); NL, normal light. Data are expressed as mean \pm S.E.M. ${ }^{\star} P<0.05$ versus controls. 
using an RIA method (Diagnostic System Laboratories, Inc. Webster, Texas, USA). The CVs were $4.7 \%$ (intraassay) and $7.2 \%$ (inter-assay).

To transform IGF-I, IGF-II, IGFBP-2 and IGFBP-3 from $\mathrm{ng} / \mathrm{ml}$ to $\mathrm{nM}$ we multiplied the single values by $0.131,0.134,0.035$ and 0.035 , respectively. Serum IL-6 and IL-1 $\beta$ were measured using an ultrasensitive ELISA method (Quantikine HS; R\&D Systems, Minneapolis, MN, USA). The CVs were 3.8 and $6.9 \%$ (intraassay) and $9.9 \%$ and $10.3 \%$ (inter-assay).

Serum TNF $\alpha$ was measured using an ultrasensitive ELISA method (Biosource International, Camarillo, CA, USA). The CVs were $11.9 \%$ (intra-assay) and $12.1 \%$ (inter-assay). Serum insulin and C-peptide were measured using a chemiluminescence method by Diagnostic Products Corporation (Los Angeles, CA, USA) for reading by Immulite2000. The intra-assay CVs were 6.5 and $7.8 \%$, respectively. The inter-assay $\mathrm{CV}$ for insulin was $7.1 \%$. The inter-assay CV for C-peptide was not calculated.

Different molecular forms of IGFBP-2 and -3 in the sera from all the patients and controls were assessed by Western immunoblotting. Equal aliquots of serum were subjected to electrophoresis on $12.5 \%$ acrylamide gels (27). The proteins were then transferred to nitrocellulose membranes and probed with specific antibodies against IGFBP-2 and -3 (Upstate Biotechnology , NY, USA; 1:2000) at $4{ }^{\circ} \mathrm{C}$ overnight as previously described $(20,21)$. The bands were visualized by enhanced chemiluminescence as recommended by the manufacturer (Amersham Pharmacia Biotech, Little Chalfont, Bucks, UK).

\section{Statistical analysis}

Statistical analysis was performed using a one-way analysis of variance (ANOVA) test followed by Scheffé's test for the growth factors. The $\mathrm{IL}$ data were not normally distributed and were analysed using Kruskal-Wallis test. The correlation analysis was performed using Pearson's or Spearman's linear regression analyses. $P<0.05$ was considered significant. Data are expressed as means \pm s.E.M. unless otherwise stated.

\section{Ethical approval}

Informed consent was obtained from the subjects and/or the parents as appropriate. The study was approved by the local Ethics Committee (University of Parma Medical School).

\section{Results}

Results in males and females were analysed together because no significant difference was found between the sexes in patients or controls. Serum concentrations of IL-1 $\beta$, IL-6, TNF $\alpha$, insulin, C-peptide, IGF-I, IGF-II, IGFBP-2 and IGFBP-3 are shown in Table 2. Serum
Table 2 Comparison of cytokines, insulin, C-peptide, IGF-I, IGF-II, IGFBP-2 and IGFBP-3 serum concentrations in CF patients and in controls.

\begin{tabular}{lcc}
\hline & CF & Controls \\
\hline IL-1 $\beta(\mathrm{ng} / \mathrm{l})$ & $1.0 \pm 0.4^{*}$ & $0.8 \pm 0.4$ \\
$\mathrm{IL}-6(\mathrm{ng} / \mathrm{l})$ & $5.0 \pm 0.8^{*}$ & $1.3 \pm 0.3$ \\
$\mathrm{TNF} \alpha(\mu \mathrm{g} / \mathrm{l})$ & $1.7 \pm 0.3^{*}$ & $0.9 \pm 0.1$ \\
Insulin $(\mathrm{IU} / \mathrm{l})$ & $11.5 \pm 2.4^{*}$ & $6.1 \pm 0.7^{\star}$ \\
$\mathrm{C}-\mathrm{peptide}(\mathrm{mg} / \mathrm{l})$ & $2.8 \pm 0.6^{*}$ & $1.9 \pm 0.1$ \\
IGF-I $(\mu \mathrm{g} / \mathrm{l})$ & $231.7 \pm 16.1^{*}$ & $302.2 \pm 26.7$ \\
IGF-II $(\mu \mathrm{g} / \mathrm{l})$ & $1027.4 \pm 57.2^{*}$ & $1264.7 \pm 63.7$ \\
IGFBP-2 $(\mu \mathrm{g} / \mathrm{l})$ & $520.5 \pm 72.9^{\star}$ & $290.9 \pm 41.2$ \\
IGFBP-3 $(\mu \mathrm{g} / \mathrm{l})$ & $4210.6 \pm 205.4$ & $4717.6 \pm 304.9$ \\
\hline
\end{tabular}

${ }^{\star} P<0.05$ versus controls.

IL-1 $\beta$, IL-6 and TNF $\alpha$ levels were significantly higher in $\mathrm{CF}$ patients compared with control subjects.

\section{Serum}

Insulin was significantly higher in the patients with respect to controls, and in the patient groups levels were higher in group 2 patients (severely affected, with lower Shwachman-Kulczycki scores) compared with group 1 (mildly affected): $18.8 \pm 4.8$ versus $7.1 \pm 1.5 \mathrm{IU} / \mathrm{l}$, respectively $(P<0.05)$. All controls had normal values (normal range, 4-25 IU/l; Fig. 1). Serum C-peptide, similarly to insulin, was higher in the patients than in the controls, with higher values in the group 2 compared with the group 1 patients: $4.3 \pm 1.2$ versus $2.0 \pm 0.3 \mathrm{mg} / \mathrm{l}$, respectively $(P<0.05)$.

Serum IGF-I and IGF-II levels were significantly lower in the patients than in the controls, whereas serum IGFBP-2 was significantly higher in patients with $\mathrm{CF}$

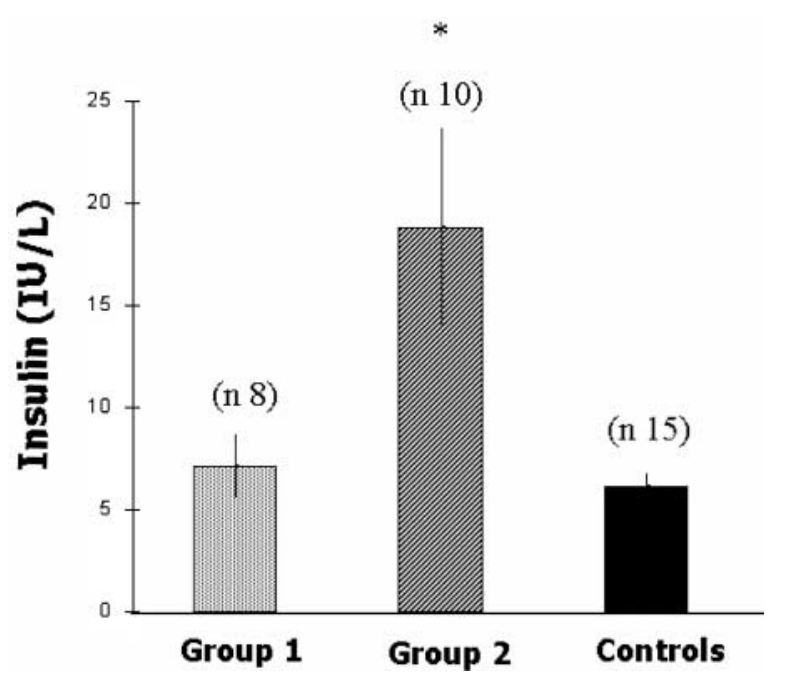

Figure 1 Insulin serum levels in CF subjects and controls, based on Shwachman-Kulczycki score. Group 1 patients are mildly affected, whereas group 2 patients are affected severely. Data are means \pm S.E.M. ${ }^{*} P<0.05$ versus controls. 
than in controls. The immunoblot analysis showed that intact IGFBP-2 was increased (Fig. 2A). Serum IGFBP-3 concentrations were similar in patients and controls. The immunoblot analysis did not show differences in the molecular forms between patients and controls (Fig. 2B).

\section{Molar ratios}

The IGF-I/IGFBP-2 and IGF-II/IGFBP-2 molar ratios were significantly lower in the patient group: $11.6 \pm 2.1$ and $3.2 \pm 0.6$ respectively versus $23.1 \pm 4.2$ and $5.4 \pm 0.7$ in controls $(P<0.05)$.

\section{Correlation analysis}

Results from the whole group are reported in Table 3. In the control subjects, a positive correlation between IGF-I and IGFBP-3 was shown $(P=0.022 ; r=0.57)$.

In the patients, IL- 6 correlated positively with C-reactive protein $(P<0.001 ; r=0.77)$ and with IGFBP-2 $(P=0.03 ; r=0.64$; Fig. 3$)$. IGFBP-2 correlated negatively with IGFBP-3 in the whole group $(P=0.025$; $r=0.54)$.

\section{Discussion}

This study shows that $\mathrm{CF}$ patients have higher serum concentrations of IL-1 $\beta$, IL- 6 , TNF $\alpha$ and IGFBP-2 compared with normal controls. Serum concentrations of IGF-I and IGF-II were significantly lower than in healthy controls, with insulin and C-peptide levels being increased. We also detected a significant positive correlation between serum IL-6 and IGFBP-2 concentrations.

For the first time we describe relationships between cytokines and the IGF/IGFBP system in CF patients, even if these must be regarded as preliminary data owing to the small number of patients enrolled in the study. Moreover, this is a cross-sectional study so we cannot comment on the natural progression of these relationships over time, and can put forward only hypotheses.

The serum concentrations of pro-inflammatory cytokines in our patients were similar to previously published data (19). Serum IGF-I levels were significantly lower in $\mathrm{CF}$ patients than in controls. At variance with previous studies this did not seem to be dependent on malnutrition or anorexia $(9,14,28,29)$ as the BMI values of these patients were normal and similar to those of controls, and total serum protein concentration was normal. Other authors have hypothesized that low serum IGF-I concentrations could be dependent on insulin hyposecretion in CF. Taylor et al. (28) described a progressive reduction of IGF-I and IGFBP-3 related to declining $\mathrm{BMI}$, and deteriorating pulmonary function, and suggested that progressive insulin deficiency might be contributing to this. Ripa et al. (29) further supported this hypothesis by showing a high frequency of insulin hyposecretion with increased serum IGFBP-1 levels, normal IGF-I and reduced growth velocity in CF. However, this group of patients had basal insulin levels similar or greater than controls. Furthermore, the low IGF-I serum levels cannot be ascribed to impaired liver function $(14,16)$ as liver function tests were normal in all the subjects. In the case of impaired liver function insulin clearance would be reduced; however, C-peptide, which is metabolized by the kidneys, showed a similar pattern to insulin, suggesting that this is very unlikely. Thus, a state of latent insulin resistance that worsens with deteriorating clinical conditions is possible (30). Insulin concentrations in our patients could be increased because of increased serum levels of TNF $\alpha$ reducing the function of the glucose transporter GLUT4 (31), which is associated with reduced glucose disposal rate and insulin resistance. However, we did not have specific data on glucose tolerance, as this was not the aim of this study. Alternatively, other mechanisms leading to altered insulin receptor signalling that have been reported could be involved: $\mathrm{IL}-6$ has also been
IGFBP2 $(\mu \mathrm{g} / \mathrm{L})$
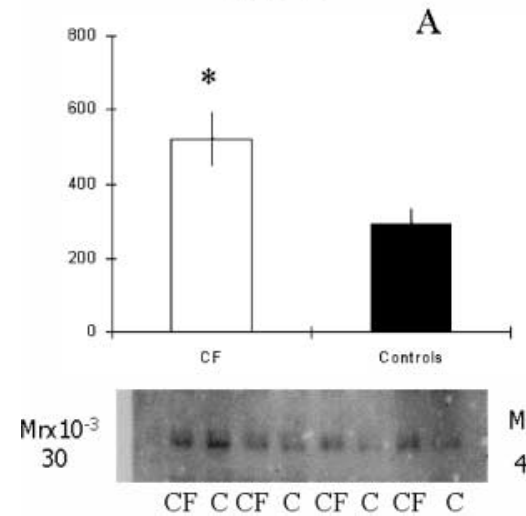

$\mathrm{CF} \mathrm{C}$ CF $\mathrm{CF} \mathrm{CF} \mathrm{C}$
IGFBP-3 $(\mu \mathrm{g} / \mathrm{L})$

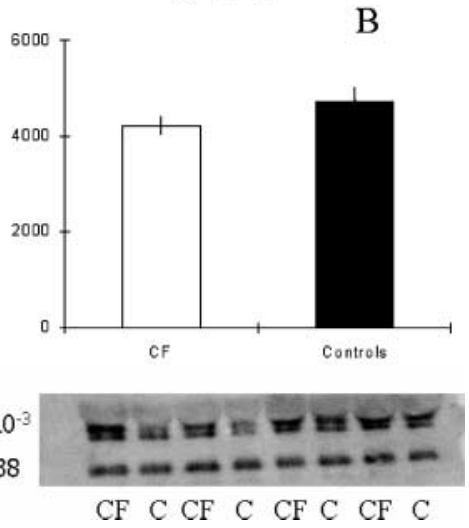

Figure 2 Serum IGFBP-2 (A) and IGFBP-3 (B) levels in cystic fibrosis patients and in controls. Data are means \pm S.E.M. ${ }^{\star} P<0.05$ versus controls. Beneath each graph is the corresponding Western immunoblot. Serum from controls is marked as $\mathrm{C}$, and from cystic fibrosis subjects with CF. These subjects were comparable for age, sex, BMI and pubertal stage. Molecular mass (Mr) markers are shown on the left in kDa. IGFBP-2 was intact, and molecular forms of IGFBP-3 were similar in all subjects. 
Table 3 Correlation analysis results in the entire group of subjects.

\begin{tabular}{llcr}
\hline & Variable & $\boldsymbol{r}$ & $\boldsymbol{P}$ value \\
\hline IGF-I & IL-6 & -0.44 & 0.014 \\
& IGFBP-2 & -0.39 & 0.018 \\
IGFBP-3 & +0.63 & $<0.001$ \\
IGF-II & IGFBP-3 & +0.49 & 0.004 \\
IGFBP-2 & IGFBP-3 & -0.37 & 0.031 \\
\hline
\end{tabular}

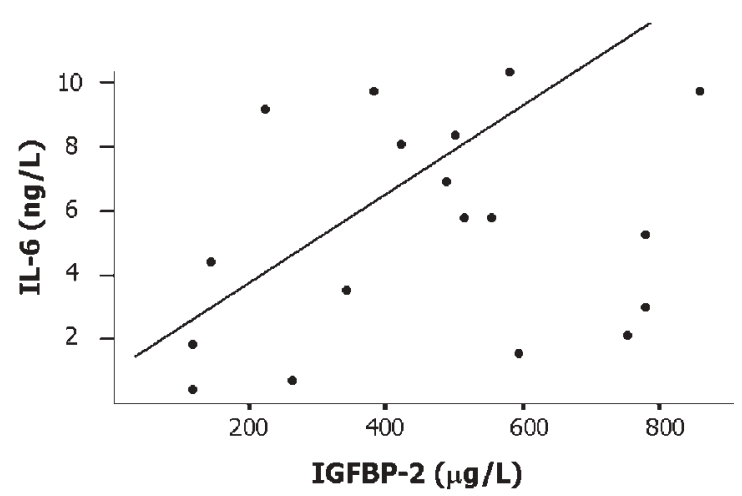

Figure 3 The correlation between serum IL- 6 and IGFBP-2 in CF patients $(P=0.03 ; r=0.64)$.

suggested to interfere with insulin action (32). Furthermore, based on very recent literature, IGF-I concentrations seem to affect insulin sensitivity, and GH and IGF-I replacement seem to be capable of improving insulin sensitivity in diabetes and CF (33-35).

Recently, it has been observed that IGF-I concentrations progressively decrease with age whereas IL- 6 tends to increase, with a possible link to morbidity in the elderly (36). In light of this, data from our study suggest that this combination could be harmful also in subjects with $\mathrm{CF}$, who present similar concentrations of IL-6 and IGF-I at a much younger age. Serum IGF-II levels have not been investigated previously and showed a similar pattern as IGF-I. IGFBP-2 concentrations were definitely increased in the patients and correlated positively with IL-6. Furthermore, the pattern was similar to that of $\mathrm{TNF} \alpha$. We previously described this increase in patients with inflammatory bowel diseases (21). These data suggest that IGFBP-2 on the one hand behaves as an acute phase protein, and on the other that the IGF/IGFBP system is modulated by some proinflammatory cytokines. It could be suggested that the serum levels could be altered in the two patients treated with oral steroids; however, it has been shown that 3 months of treatment with steroids reduce, not increase, IGFBP-2 serum levels (37).

IGFBP-3 serum concentrations were similar in the patients and controls although they tended to be lower in patients with the most severe clinical state, and we did not find any relationship with insulin at variance with previously published data $(28,29)$.
This helps to explain why the IGF-I/IGFBP-3 molar ratios were similar in $\mathrm{CF}$ and healthy subjects. The IGF-I/IGFBP-2 and IGF-II/IGFBP-2 molar ratios were strongly reduced in CF, which would confirm a possible impaired compensatory mechanism for free IGF-I and IGF-II in CF.

Moreover, we did not find different molecular forms of IGFBP-2 and IGFBP-3 in patients and controls that could suggest increased proteolysis. The negative relationship between IGFBP-3 and IGFBP-2, both in the whole group of subjects enrolled in the study and in the patients, further strengthens the hypothesis that overall IGF bioactivity is blunted as the two peptides seem to go in opposite directions; if IGFBP-3 decreases, possibly increasing free IGF-I, IGFBP-2 increases, binding and reducing IGF-I bioavailability. The data of this study therefore suggest that the IGF/IGFBP system is modulated to reduce IGF-I and IGF-II bioactivity and thus their anabolic and proinsulin activity.

In conclusion, it can be speculated that chronic inflammation is an important modulator of the IGF/IGFBP system in CF, and represents a possible mechanism for peripheral resistance to GH. This is in consideration of the fact that the Shwachman-Kulczycki score uses general activity, a physical examination, nutrition and X-ray findings. Nutritional status in this patient group was very good and cannot have played an important role, whereas inflammatory cytokines were significantly increased and correlated with growth factors. The overall data suggest a dysregulation which influences bioactivity of IGFs. Furthermore, these data prompt considerations of alternative or additional treatments in CF. They support the use of anti-inflammatory drugs such as ibuprofen (38), possibly new anti-cytokine drugs (39), and even GH and IGF-I.

\section{Acknowledgements}

Preliminary data were presented as an abstract at the 42nd ESPE meeting in Ljubljana, Slovenia, 18-21 September 2003. We are indebted to Dr G Pisi for helping with the calculation of the Shwachman-Kulczycki score and to our nurses Cristina Colombini and Aurelia Pantaleo for their help in collecting the data. We are grateful to the young doctors and students who agreed to participate in this study as controls. We thank Dr Rossana di Marzio for all her help with administrative work related to this research. This study was supported by a grant from the Ministry of Education, University and Research in Italy (2001-2002).

\section{References}

1 Markowitz J, Grancher K, Rosa J, Aiges H \& Daum F. Growth failure in pediatric inflammatory bowel disease (IBD). Journal of Pediatric Gastroenterology and Nutrition $199316373-380$. 
2 Markowitz J \& Daum F. Growth impairment in pediatric inflammatory bowel disease. American Journal of Gastroenterology 1994 $89319-326$.

3 Motil JK, Grand RJ, Davis-Kraft L, Ferlic LL \& O'Brian Smith E. Growth failure in children with inflammatory bowel disease: a prospective study. Gastroenterology 1993105 681-691.

4 Brain CE \& Savage MO. Growth and puberty in chronic inflammatory bowel disease. Baillières's Clinical Gastroenterology 19948 $83-100$.

5 Booth IW. The nutritional consequences of gastrointestinal disease in adolescence. Acta Paediatrica Scandinavica Suppl 1991 $37391-102$.

6 Littlewood JM \& Wolfe SP. Control of malabsorption in cystic fibrosis. Paediatric Drugs 20002 205-222.

7 Golden MH. Is complete catch-up possible for stunted malnourished children? Euopean Journal of Clinical Nutrition $1994 \mathbf{4 8}$ S58-S70.

8 Food and Nutrition Board. In National Research Council Recommended Dietary Allowances, 10th edn, pp 174-184,. Washington DC: National Academy Press, 1989.

9 Laursen EM, Juul A, Lanng S, Hoiby N, Koch C, Muller J \& Skakkebaek NE. Diminished concentrations of insulin-like growth factor I in cystic fibrosis. Archives of Disease in Childhood $199572494-497$.

10 Lai H-C, Kosorok MR, Sondel SA, Chen ST, Fitzsimmons SC, Green CG, Shen G, Walker S \& Farrell PM. Growth status in children with cystic fibrosis based on the National Cystic fibrosis patient registry data: evaluation of various criteria used to identify malnutrition. Journal of Pediatrics 1998132 478-485.

11 Hardin DS \& Sy JP. Effects of growth hormone treatment in children with cystic fibrosis: the National Cooperative Growth Study experience. Journal of Pediatrics 1997131 S65-S69.

12 Morison S, Dodge JA, Cole TJ, Lewis PA, Coles EC, Geddes D, Russell G, Littlewood JM \& Scott MT. Height and weight in cystic fibrosis: a cross sectional study. Archives of Disease in Childhood 199777 497-500.

13 Rosenfeld RG, Landon C, Lewiston, Nagashima R \& Hintz RL. Demonstration of normal somatomedin concentrations in cystic fibrosis. Journal of Pediatrics $198199252-254$.

14 Grant DB, Hambley J, Becker D \& Pimstone BL. Reduced sulphation factor in undernourished children. Archives of Disease in Childhood $1973 \mathbf{4 8} 596-600$.

15 Lebl J, Zahradnikova M, Bartosova J, Zemkova D, Pechova M \& Vavrova V. Insulin-like growth factor-I and insulin-like growth factor-binding protein-3 in cystic fibrosis: a positive effect of antibiotic therapy and hyperalimentation. Acta Paediatrica 200190 $868-872$.

16 Laursen EM, Lanng S, Rasmussen MH, Koch C, Skakkebaek NE \& Muller J. Normal spontaneous and stimulated GH levels despite decreased IGF-I concentrations in cystic fibrosis patients. European Journal of Endocrinology $1999140315-321$.

17 De Benedetti F, Alonzi T, Moretta A, Lazzaro D, Costa P, Poli V, Martini A, Ciliberto G \& Fattori E. Interleukin 6 causes growth impairment in transgenic mice through a decrease in insulinlike growth factor-1. Journal of Clinical Investigation 199799 $643-650$.

18 De Benedetti F, Meazza C, Oliveri M, Pignatti P, Vivarelli M, Alonzi T, Fattori E, Garrone S, Barreca A \& Martini A. Effect of IL-6 on IGF binding protein-3: a study in IL-6 transgenic mice and in patients with systematic juvenile idiopathic arthritis. Endocrinology $2001 \mathbf{4 2} 4818-4826$.

19 Berger M. Inflammatory mediators in cystic fibrosis lung disease. Allergy and Asthma Proceedings 200223 19-25.

20 Street ME, Miraki-Moud F, Sanderson IR, Savage MO, Giovannelli G, Bernasconi S \& Camacho-Hubner C. Interleukin$1 \beta$ (IL-1 $\beta$ ) and IL-6 modulate insulin-like growth factor-binding protein (IGFBP) secretion in colon cancer epithelial (Caco-2) cells. Journal of Endocrinology 2003179 405-415.

21 Street ME, de'Angelis GL, Camacho-Hubner C, Giovannelli G, Ziveri MA, Bacchini PL, Bernasconi S, Sansebastiano G \&
Savage MO. Relationships between serum IGF-I, IGFBP-2, interleukin-1 and interleukin-6 in inflammatory bowel disease. Hormone Research 200361 159-164.

22 Marshall WA \& Tanner J. Variations in pattern of pubertal changes in girls. Archives of Disease in Childhood $19694 \mathbf{4}$ 291-303.

23 Marshall WA \& Tanner J. Variations in pattern of pubertal changes in boys. Archives of Disease in Childhood 196945 13-23.

24 Cacciari E, Milani S, Balsamo A, Dammacco F, De luca F, Chiarelli F, Pasquino AM, Tonini G \& Vanelli M. Italian cross-sectional growth charts for height, weight and BMI (6-20yr). European Journal of Clinical Nutrition 200256 171-180.

25 Polgar G \& Promadhat V. Pulmonary Function Testing in Children: Techniques and Standards. Philadelphia: WB Saunders, 1971.

26 Shwachman H \& Kulczycki LL. Long-term study of 105 patients with cystic fibrosis. American Journal of Disease in Childhood $1958966-15$.

27 Laemmli UK. Cleavage of structural proteins during the assembly of the head of bacteriophage T4. Nature $1970 \mathbf{2 7 7} 680-685$.

28 Taylor AM, Bush A, Thomson A, Oades PJ, Marchant JL, BruceMorgan C, Holly J, Ahmed L \& Dunger DB. Relation between insulin-like growth factor-I, body mass index, and clinical status in cystic fibrosis. Archives of Disease in Childhood 199776 304-309.

29 Ripa P, Robertson I, Cowley D, Harris M, Masters B \& Cotterill AM. The relationship between insulin secretion, the insulin-like growth factor axis and growth in children with cystic fibrosis. Clinical Endocrinology 200256 383-389.

30 Hardin DS, LeBlanc A, Lukenbough S \& Seilheimer DK. Insulin resistance is associated with decreased clinical status in cystic fibrosis. Journal of Pediatrics 1997130 948-956.

31 Hardin DS, LeBlanc A, Marshall G \& Seilheimer DK. Mechanisms of insulin resistance in cystic fibrosis. American Journal of Physiology Endocrinology and Metabolism 2001281 E1022-E1028.

32 Grimble RF. Inflammatory status and insulin resistance. Current Opinion in Clinical Nutrition and Metabolic Care 20025 551-559.

33 Yuen K, Frystyk J, Umpleby M, Fryklund L \& Dunger D. Changes in free rather than total insulin-like growth factor-I enhance insulin sensitivity and suppress endogenous peak growth hormone (GH) release following short-term low-dose GH administration in young healthy adults. Journal of Clinical Endocrinology and Metabolism 200489 3956-3964.

34 Simpson HL, Jackson NC, Shojaee-Moradie F, Jones RH, RussellJones DL, Sonksen PH, Dunger DB \& Umpleby AM. Insulin-like growth factor I has a direct effect on glucose and protein metabolism, but no effect on lipid metabolism in type I diabetes. Journal of Clinical Endocrinology and Metabolism $200489425-432$.

35 Bucuvalas JC, Chernausek SD, Alfaro MP, Krug SH, Ritschel W \& Wilmot RW. Effect of insulin-like growth factor-I treatment in children with cystic fibrosis. Journal of Pediatric Gastroenterology and Nutrition 200133 576-581.

36 Cappola AR, Xue Q-L, Ferrucci L, Guralnik JM, Volpato S \& Fried LP. Insulin-Like growth factor I and interleukin-6 contribute synergistically to disability and mortality in older women. Journal of Clinical Endocrinology and Metabolism $2003 \mathbf{8 8} 2019-2025$.

37 Baxter RC, Holman SR, Corbould A, Stranks S, Ho PJ \& Braund W. Regulation of the insulin-like growth factors and their binding proteins by glucocorticoid and growth hormone in nonislet cell tumor hypoglycemia. Journal of Clinical Endocrinology and Metabolism $1995 \mathbf{8 0} 2700-2708$.

38 Konstan MW, Byard PJ, Hoppel CL \& Davis PB. Effect of high-dose ibuprofen in patients with cystic fibrosis. New England Journal of Medicine $1995332848-854$.

39 Ryu H, Soltys J, Saadane A \& Berger M. Effect of TNFR:Fc on response of CFTR-/-mice to acute intratracheal challenge with P. aeruginosa. Pediatric Pneumology 200325 (Suppl) 253.

Received 27 April 2005

Accepted 29 September 2005 